\title{
Apropriação da informação: o processo de construção do conhecimento de catadores de materiais recicláveis
}

\author{
Suely Henrique Gomes \\ Doutora; Universidade Federal de Goiás, Goiânia, GO, Brasil; \\ suelyhenriquegomes@gmail.com \\ Geisa Müller de Campos Ribeiro \\ Mestre; Universidade Federal de Goiás, Goiânia, GO, Brasil; \\ geisamuller@hotmail.com \\ Laura Vilela Rodrigues Rezende \\ Doutora; Universidade Federal de Goiás, Goiânia, GO, Brasil; \\ lauravil.rr@gmail.com
}

\begin{abstract}
Resumo: Este artigo aborda o processo de construção do conhecimento de catadores de materiais recicláveis organizados em cooperativas e assessorados pelo projeto de incubação social da Universidade Federal de Goiás, a partir do tensionamento entre o conhecimento científico e o comum. No que concerne aos aspectos metodológicos, trata-se de pesquisa qualitativa e quanto aos objetivos caracteriza-se como descritiva - exploratória. Os dados foram coletados via observação participante. Dentre os principais resultados, destaca-se que a construção do conhecimento dos catadores inseridos no contexto de incubação social ocorre via interação significativa. Isto é, quando, por meio do diálogo e imerso em estratégias metodológicas criativas, o sujeito significa as informações, provocando mudanças em sua base simbólica de conhecimento. Essa transformação ocorre somente mediante processo comunicativo. Por meio da interação, o sujeito é problematizado ao exercer a análise crítica sobre sua realidade atual como catador. Assim, ele ressignifica sua identidade, desenvolve seu sentimento de pertença, estabelece os vínculos com o grupo que trabalha e se apropria das informações que são mediadas pela equipe gestora de incubação.
\end{abstract}

Palavras-chave: Comunicação. Construção do conhecimento. Apropriação da informação. Incubação social. Catadores de materiais recicláveis.

\section{Introdução}

Diversas pesquisas têm apontado que no Brasil a diferença na distribuição de renda é uma realidade cada vez mais preocupante e que eleva o grau de desigualdade social, em comparação com outros países. Neste contexto, inserem-se os catadores de materiais recicláveis, vivendo às margens da 
visibilidade social e, em sua maioria, com históricos de marginalização e de trabalho individual aprendido nas ruas e nos lixões. Suas experiências trazem de maneira recorrente o sofrimento vivido por desgastes (físicos e psicológicos) e desvalorização, uma vez que estão excluídos do mercado de trabalho formal.

Por não desempenharem uma atividade reconhecida e valorizada socialmente, esses grupos estão à margem da sociedade e, segundo categorização econômica, encontram-se na faixa de pobreza. Eles vagam pelas ruas a pé por vários quilômetros, procurando recicláveis. Durante o trabalho, ficam expostos a ferimentos produzidos por objetos cortantes e são submetidos à manipulação prolongada de materiais insalubres que debilitam sua saúde. Aquilo que recebem como pagamento pela coleta não é suficiente para o seu sustento e de sua família (SANTOS, 2005).

Diversas experiências relacionadas ao cooperativismo, iniciadas nos meados do século XIX, mostram que o trabalho coletivo, ao gerar emprego e renda, se estabelece como alternativa de inclusão social, produção e distribuição de riqueza (FRANÇA; MARTINO; HOHLFELDT, 2002). Nesse âmbito, a economia solidária, como um dos desdobramentos do movimento associativo, representa um projeto de sociedade que exige novos valores e a construção da autonomia dos empreendimentos com bases democráticas (GADOTTI, 2009). Portanto, ao se organizarem, estes grupos contam com o apoio de instituições públicas ou privadas, como é o caso dos programas de incubadoras sociais universitárias.

Para Etzkowitz (2013), a incubadora é a expressão da missão educacional da Universidade, assim como de desenvolvimento econômico e de serviços. Logo, funciona como mecanismo de interação. Seus espaços são locais de trocas de experiências e desenvolvimento de metodologias criativas, visando aliar o saber popular (do cooperado) com o conhecimento técnico-científico (gestores da incubadora) em ações efetivas e reaplicáveis que propiciam inclusão e desenvolvimento social.

Por conseguinte, a incubadora social da Universidade Federal de Goiás (UFG) presta assistência no que se refere à organização, formação e orientação de empreendimentos solidários, contribuindo para a demanda de emprego, renda 
e de melhoria da qualidade de vida da comunidade. Colabora ainda para que os empreendimentos sobrevivam no setor econômico, mediante a construção da autogestão. Em linhas gerais, sua atuação se dá em duas grandes perspectivas:

a) no quadro social dos sujeitos, busca a autoafirmação dos indivíduos e a emancipação de sua identidade (conquista inicial);

b) e na estruturação dos empreendimentos e na gestão organizacional autônoma.

Contudo, é preciso considerar os desafios a serem superados nessa relação entre os atores envolvidos - incubadora/cooperativa -, tendo em vista as dinâmicas culturais (valores, símbolos e linguagem) que cada indivíduo traz para o processo e seu universo distinto. Vale assinalar, nesse sentido, que os conhecimentos considerados populares, do senso comum, são pautados nas experiências e vivências práticas dos catadores, e os conhecimentos teóricos científicos são produzidos nas universidades. Em virtude da valorização dos conhecimentos científicos pela sociedade, professores e gestores da incubadora, ao se depararem com uma realidade que é diferente do seu universo, podem desenvolver mecanismos de manipulação e de descarte do que é considerado não científico.

Portanto, para refletir sobre o processo de construção do conhecimento existente na interação entre as realidades e os modos distintos de produção de saberes, esta pesquisa tem como objetivo compreender o processo de construção do conhecimento de catadores de materiais recicláveis organizados em cooperativas e assessorados pelo programa de incubação social da Universidade Federal de Goiás.

O processo de construção do conhecimento para esta pesquisa está relacionado às interações e estratégias dialógicas das ações desenvolvidas pelo programa de incubação social da UFG nos empreendimentos. Seguindo o pensamento de Freire (2013) para abordar a realidade em estudo, a construção do ambiente cooperativo e de autogestão ocorre nos momentos de troca de experiências, intervenções e problematizações que são levantadas em conjunto com os sujeitos cooperados. Em outras palavras, busca-se no processo comunicativo dialógico o desenvolvimento gradativo do catador e do grupo 
rumo a sua autonomia e ao avanço de suas diferentes competências e habilidades sociais necessárias à prática da gestão coletiva.

\section{Incubação Social: interação Universidade - empreendimentos populares} de autogestão

A Incubadora Social da Universidade Federal de Goiás é um programa vinculado à Pró-Reitoria de Extensão e Cultura (PROEC) que, por meio do processo de integração com diversos setores da sociedade, oportuniza a melhoria da condição de vida da comunidade e minimiza os problemas sociais nos locais de sua atuação.

A Política Nacional de Extensão Universitária (FORPROEX, 2012) conceitua a extensão como processo educativo, cultural e científico que articula o ensino (formação de pessoas) e a pesquisa (conhecimento) de forma associada, possibilitando a relação transformadora entre Universidade e sociedade. Logo, é considerada uma ponte que oportuniza a troca de saberes no processo dialético de teoria/prática.

É por meio desse processo dialético que as incubadoras sociais participam, na prática, da organização, formação, orientação e acompanhamento de forma sistematizada dos empreendimentos populares de autogestão. Segundo Culti (2009), a interação entre os atores, nessa perspectiva dialética, viabiliza a construção, desconstrução e reconstrução de conhecimentos para todas as partes, uma vez que:

a) valoriza o saber acumulado das pessoas e do grupo com vistas à inclusão social econômica;

b) acrescenta conhecimentos básicos de trabalho cooperativo e técnicas específicas de produção e gestão administrativa;

c) orienta para o mercado;

d) une saber popular e saber científico numa tentativa de transformação de prática cotidiana inter-relacionando as atividades de ensino, pesquisa e extensão;

e) é um processo educativo que modifica as circunstâncias, os indivíduos e a sociedade na sua maneira de ser e agir. 
Mediante as ações de diálogo desenvolvidas na interação, os conhecimentos acumulados por mecanismos diferentes se misturam e se produzem. Essa dinâmica oportuniza o surgimento de conhecimentos novos, que influenciam tanto quem produz quanto quem irá utilizar tais conhecimentos. Consequentemente, na construção do conhecimento, os catadores inseridos no processo de apropriação podem significar ou ressignificar esse conhecimento, descartando-o, produzindo-o, modificando-o ou reproduzindo-o.

Conforme Gomes (1999), o termo "apropriação" pode nos remeter tanto à visão utilitarista de algo, no sentido de estar adequado para o uso instrumental na resolução de algum problema ou situação, quanto para o universo de ordem simbólica - ligada à estrutura mental e ao construto simbólico cultural do sujeito que contribui para a construção de sua realidade. A autora esclarece ainda que a apropriação é resultante de ações coletivas de caráter cognitivo, social e político e pode ser de natureza técnico-instrumental imbuída de racionalidade, ou apoiada nas estruturas valorativas (hábitos, costumes, crenças, preferências) derivadas do contexto cultural.

Nessa perspectiva, os interesses manifestados no âmbito do indivíduo ou grupos seriam materializados na medida em que se consegue, via processo de argumentação, expectativas, comprometimentos, manipulação e dominação, a mobilização de recursos materiais, cognitivos e sociais em torno de interesses comuns.

Se a apropriação do conhecimento é pautada em recursos materiais, sociais e cognitivos, tendo em vista os diferentes tipos de capital que o indivíduo traz para o processo, então torna-se pertinente considerar que a qualidade e estruturação das ações voltadas para a apropriação do conhecimento se dariam sob a dinâmica do que Bourdieu (1999) denomina illusio. Isto porque o sujeito do conhecimento é portador de identidade coletiva, faz parte de determinado grupo social e ocupa determinado lugar cuja dinâmica e realidade são interiorizadas por ele.

Ou seja, a apropriação do conhecimento é um jogo social e suas regras, alvos, capitais e prêmios devem ser reconhecidos e perseguidos, conforme os interesses dos jogadores. Não há nenhuma ação sem interesse illusio em jogo. 
Esse jogo se desenvolve como "[...] o produto da relação de cumplicidade ontológica entre as estruturas incorporadas (habitus) e as estruturas objetivas do espaço social.” (BOURDIEU, 1996, p. 139-140).

O conceito de illusio remete ao "compromisso existencial intenso dos agentes com os bens disputados em determinado jogo" (PETERS, 2012, p. 238) e está atrelado a outras duas categorias conceituais de Bourdieu - habitus e campo -, como se lê:

\begin{abstract}
Como dimensão "libidinal" de um habitus, os interesses específicos de um agente são engendrados pelos estímulos sensibilizadores duradouros próprios de uma certa constelação de condições sociais de existência [habitus], em um processo prolongado de "educação sentimental" (para tomar de empréstimo a expressão de Flaubert). A implicação disso é que diferentes cenários de socialização fazem florescer interesses distintos e "encaminham" os agentes para campos diferenciados, cada um com um tipo de illusio irredutível ao outro, o que faz com que os investimentos típicos de um campo pareçam sem sentido ou absurdos para aqueles situados em um universo distinto e socialmente predispostos a reconhecer como dignos de persecução outros objetivos e valores. (PETERS, 2012, p. 238).
\end{abstract}

O emaranhado social estabelecido entre illusio, habitus e campo funda em si a miséria do mundo. A violência e privação simbólica inerentes a essa dinâmica produzem autoimagens, autoidentidades e "persona coletiva" de excluídos (outsiders) que podem perpetuar a miséria desqualificante, ou seja, uma "[...] espécie de miséria coletiva que fere, como uma fatalidade, todos aqueles que estão amontoados nos lugares de rejeição social.” (BOURDIEU, 2008, p. 85). Miséria essa que não se supera somente com a redistribuição de renda. Há de se mudar o habitus, o campo e o illusio no processo de inclusão e promoção de cidadania.

Porém, por se tratar de sistema aberto, há possibilidade de se romper com os mecanismos desse jogo de interesses que produzem esse efeito de destino que está inscrito na pertença de um grupo estigmatizado. Reconstruir "a razão de ser" dessa persona coletiva é o objetivo das ações de produção e apropriação do conhecimento que passa, inclusive, pela reelaboração das autoimagens, e autoidentidades. Essa possibilidade só se deixa entrever via ação 
reflexiva pautada nos princípios de comunicação emancipatória, inclusiva e não institucionalizada.

Nesse sentido, para esta pesquisa toma-se o conceito de comunicação como processo de trocas simbólicas, em que, no movimento de interação, os indivíduos são portadores e, ao mesmo tempo, produtores de cultura, na medida em que os sujeitos interagem, compartilham e criam novos sentidos. Sendo assim, a cultura pressupõe e exige comunicação, pois é na cultura que a comunicação encontra sua possibilidade de realização, de fissuras e rupturas com o status quo. É nos valores centrais da cultura que a comunicação encontra sua orientação e a ela retorna.

Por essa razão, Freire (2013) propõe a construção do diálogo como princípio de trabalho, ou seja, o reconhecimento da capacidade do indivíduo de construir relações com outros e com o mundo. Nesse movimento, seus valores e aspectos culturais são devidamente reconhecidos, valorizados e respeitados. Ao invés de a Universidade (campo científico) colocar-se de forma autoritária, verticalizada, e dicotomizada entre sujeito e objeto, abre-se para a relação de atuantes, pois afinal, tudo o que envolve transmissão, transferência, invasão não é comunicação. Para o referido autor, a comunicação é coparticipação de sujeitos no ato de conhecer a situação social onde as pessoas criam conhecimento juntas.

Assim, entende-se que o diálogo entre os saberes, interesses e sujeitos pertencentes a grupos sociais tão distintos constitui o que deve ser aplicado à realidade de projetos de incubação social. Entretanto, não se trata de tarefa fácil. Existem muitos entraves e resistências no processo, principalmente porque os catadores estão condicionados à realidade histórico-cultural (produto de suas ações) de vida nos galpões e nas ruas - sua illusio é cristalizada em subjetividade de exclusão e fixada em determinado campo social. Por certo, estruturas verticais e relações rígidas historicamente os levam à condição de oprimidos. Grande parte dos catadores desconfiam de si mesmo e são inseguros de suas próprias capacidades. A educação que lhes foi negada tira seu direito de dizer sua palavra e revela que "[...] a dificuldade em dialogar não tem razões no 
seu próprio querer, mas nas estruturas sociais enquanto fechada e opressora que determinam suas atitudes." (FREIRE, 2013, p. 61).

Em outras palavras, a dialogicidade necessária para projetos de incubação social para apropriação e construção de conhecimentos sugere o repensar dessa relação, para a reflexão de novas práticas e ações que podem ser desenvolvidas em meio à pluralidade cultural que permeia a realidade acadêmica e a realidade de empreendimentos sociais.

\section{Métodos}

A pesquisa empregada neste estudo é a qualitativa. De acordo com Diehl e Tatim (2004), é a abordagem que utiliza a subjetividade na compreensão e construção do objeto em estudo, sendo, portanto, descritiva e exploratória. Pesquisas dessa natureza são utilizadas para apresentar características de determinada população ou fenômeno e oportunizam maior proximidade com o problema.

Dentre as possibilidades da pesquisa qualitativa, adotou-se como procedimento técnico a observação participante, cujos instrumentos incluem, além da vivência e permanência no local de pesquisa, entrevistas informais e semiestruturadas e a pesquisa documental.

O universo da pesquisa é composto por duas cooperativas que fazem parte do projeto de incubação social da Universidade Federal de Goiás, localizadas na cidade de Goiânia. São 28 catadores associados e sete gestores de incubação que assessoram essas cooperativas.

Os depoimentos dos participantes da pesquisa foram obtidos no período de março a novembro de 2015 e registrados como "notas de campo". Durante as vivências in loco da pesquisadora houve momentos de observação direta (rodas de conversas, participação nas atividades) e indireta (acompanhamento de atividades da equipe gestora de incubação social).

Os instrumentos utilizados, temas, categorias de análises e fontes para a pesquisa estão explicitados no Quadro 1, a seguir. 
Quadro 1 - Procedimentos técnicos

\section{Instrumento}

\section{Observação (Momentos de Interações)}

Categorias de análise: diálogo entre ambos (catador e agente de incubação social); as problematizações e o processo de aprendizagem; significação e ressignificação dos cooperados sobre o novo modo organizacional autogestionário e cooperativo de trabalho.

\begin{tabular}{|c|c|c|}
\hline \multicolumn{3}{|c|}{ Entrevista semiestruturada e informal } \\
\hline $\begin{array}{l}\mathbf{G} \\
\mathbf{R}\end{array}$ & Catador & Agente de incubação social \\
\hline & $\begin{array}{l}\text { Categorias de análise: confiança, } \\
\text { cooperação, gestão organizacional, } \\
\text { autoconfiança e identidade. }\end{array}$ & $\begin{array}{l}\text { Categoria de análise: interação entre os } \\
\text { saberes, dificuldades nas orientações e } \\
\text { resistências dos cooperados. }\end{array}$ \\
\hline \multicolumn{3}{|c|}{ Pesquisa documental } \\
\hline $\begin{array}{l}\mathbf{F} \\
\mathbf{O} \\
\mathbf{N} \\
\mathbf{T} \\
\mathbf{E} \\
\mathbf{S}\end{array}$ & \multicolumn{2}{|c|}{$\begin{array}{l}\text { - Projeto de incubação da Incubadora Social; } \\
\text { - } \\
\text { - } \quad \text { Rerfil econômicórios de visitas técnicas da equipe gestora. }\end{array}$} \\
\hline
\end{tabular}

Fonte: Elaborado pelas autoras.

As entrevistas semiestruturadas foram realizadas em reuniões préagendadas com os catadores nas cooperativas. Para as entrevistas informais não existiram temas pré-estabelecidos e foram realizadas desde o início de imersão ao campo.

Estimava-se entrevistar vinte e oito cooperados, ou seja, a totalidade dos catadores dos dois empreendimentos. Mas isso não foi possível, devido às diversas greves do Programa Coleta Seletiva de Goiânia. O Programa Goiânia Coleta Seletiva visa evitar que materiais recicláveis sejam encaminhados para o aterro sanitário. Aumentar a vida útil desses materiais significa, ao mesmo tempo, dar a oportunidade para que seja separado, mediante trabalho desenvolvido pelas cooperativas de catadores. Quando o programa não cumpre seu compromisso com a comunidade, muitos cooperados perdem sua atividade e são obrigados a procurar outras alternativas de sobrevivência. A falta de materiais recicláveis nas cooperativas é, portanto, umas das justificativas para a 
alta rotatividade de catadores associados. Por essa razão, foi possível entrevistar somente dez catadores, cujos perfis são apresentados no Quadro 2, que segue.

Quadro 2 - Perfil dos catadores

\begin{tabular}{|l|l|l|l|l|}
\hline \multicolumn{2}{|c|}{ Quadro total de membros } & \multicolumn{3}{c|}{ Membros que atualmente trabalham (2015) } \\
\hline Cooperativa 1-14 cooperados & \multicolumn{3}{c|}{ Sete catadores cooperados } \\
\hline Cooperativa 2-14 cooperados & \multicolumn{3}{|c|}{ Três catadores cooperados } \\
\hline Gênero & Alfabetizados & Escolaridade & Idade & Filhos \\
\hline $\begin{array}{l}\text { Homens: dois } \\
\text { Mulheres: oito }\end{array}$ & $\begin{array}{l}\text { Sim: oito } \\
\text { Não: dois }\end{array}$ & Ensino Fundamental & Entre 26 e 68 & $\begin{array}{l}\text { Entre dois e } \\
\text { cinco }\end{array}$ \\
\hline Habitação & Próprias (casas do Programa Minha Casa Minha Vida) \\
\hline Principal fonte de Renda & Cooperativa \\
\hline $\begin{array}{l}\text { Beneficiários de programas } \\
\text { assistenciais }\end{array}$ & (um) Bolsa Família \\
\hline Estado civil & Solteiros \\
\hline
\end{tabular}

Fonte: Elaborado pelas autoras.

Realizaram-se cinco entrevistas com um representante de cada área de atuação da equipe gestora do projeto de incubação social, a saber: contabilidade, comunicação, autogestão, assistência social e coordenação-geral da incubadora. Estes foram escolhidos conforme o tempo de atuação e experiência na incubadora.

A pesquisa documental trouxe dados complementares às outras formas de obtenção de dados já mencionadas. Essa etapa possibilitou a compreensão do projeto de incubação social da Universidade.

Para a análise, os dados coletados foram separados em categorias seguindo a concordância dos temas estabelecidos para a extração das expressões-chave em resposta aos questionamentos levantados.

Este estudo foi aprovado pelo Comitê de Ética em Pesquisa da Universidade Federal de Goiás, tendo em vista que contempla metodologicamente observação participante e entrevistas com grupos em vulnerabilidade social.

\section{Resultados}

Consideram-se na discussão dos resultados obtidos os seguintes aspectos: (1) a interação dialógica significativa para a construção de conhecimento; (2) a problematização para a apropriação da informação como processo de 
aprendizagem para o catador; (3) a ressignificação da identidade do catador; (4) as relações de pertencimento à cooperativa.

Esses elementos foram identificados como pertencentes ao processo de construção do conhecimento para que o catador se aproprie das informações e mude sua realidade.

\subsection{O processo comunicativo: a interação dialógica significativa para a construção de conhecimento}

A interação faz parte da constituição da humanidade e, como contexto da comunicação, se configura como processo social de produção e compartilhamento de sentidos mediante trocas simbólicas complexas (FRANÇA; MARTINO; HOHLFELDT, 2002).

A cultura, como condição produtora do universo simbólico dos indivíduos, possibilita a comunicação. Morin (1991) afirma que a comunicação está sempre ligada a padrões culturais. E os indivíduos, como portadores de cultura, também são ao mesmo tempo seus produtores. Portanto, a comunicação como elemento de cultura é um modo de negociação simbólica entre o imaginário e o real, o que permite a construção social dos sistemas de significação e sua circulação.

No processo de incubação social, os gestores são considerados mediadores para a construção do conhecimento entre os catadores. Para tanto, instituem estratégias dialógicas para a interação significativa, o que demanda a instauração da confiança, para a realização de discussões, análises críticas e a busca de soluções de forma democrática para os problemas coletivos. Os gestores, assim, desenvolvem metodologias criativas, de caráter único, geradas e moldadas com base na realidade dos catadores.

Nesse âmbito, há relação entre o saber popular, oriundo do trabalhador, com o saber científico/acadêmico pertencente à equipe gestora da incubadora. Esses saberes misturam-se, tencionam-se e são utilizados como matéria-prima por ambos, a fim de se tornarem aplicáveis ou mais adequados à natureza do empreendimento e do trabalhador associado. Apesar da complexidade dessa 
ação, a interação torna-se significativa quando há mudança na base simbólica de conhecimento dos envolvidos.

Para Freire (2013), o sentido de comunicação é "estar em direção do outro", via movimento de coparticipação dos sujeitos no ato de pensar. Isso exige reciprocidade dialética, que não pode ser rompida. Quando se reconhecem como sujeitos, os indivíduos podem compartilhar os mesmos símbolos em relação de igualdade. Trata-se do conhecimento que é construído por intermédio do encontro e das relações de ambos em busca da significação dos significados (LIMA, 1981).

A estratégia do projeto de incubação identificada para a potencialização da interação e abertura ao diálogo entre as partes é a técnica chamada de torvelino ou tempestade de ideias. O grupo se reúne em formação circular, significando igualdade entre todos os participantes, e cada indivíduo tem seu tempo definido para análise do problema em discussão, assim como para propor soluções.

Segundo Sampaio et al. (2014), a formação circular funciona como potência metodológica de confronto de realidade e leitura do mundo no movimento que percorre a ação, reflexão e transformação, visando à apropriação do diálogo que se pretende estabelecer. É uma estratégia de horizontalização das relações de poder. Para os cooperados, refere-se a um espaço de construção de saber, de discussões e de oportunidade de fala.

Por conseguinte, as rodas de conversas, constituídas como encontros dialógicos, criam possibilidades para produção e ressignificação de sentido dos catadores. Os sujeitos que as compõem se posicionam, dialeticamente, como atores históricos e sociais críticos e reflexivos diante da realidade. Nesse processo interativo, a fala é democrática e emerge como signo de valores, normas, cultura, práticas e discurso, além de modos de negociação entre sujeitos.

Em suma, a construção do diálogo por meio das estratégias estabelecidas oportuniza a interação significativa. O processo comunicativo gera a circulação, produção de significados e ressignificação de sentido. Se há produção de significado, há apropriação. 


\subsection{Problematização: a apropriação da informação como processo de aprendizagem para o catador}

$\mathrm{O}$ catador vive uma realidade marginalizada e estigmatizada pela sociedade.

Nesse contexto de dificuldade, assume identidades contraditórias e deslocadas, formadas e transformadas pela construção de sistemas classificatórios pelo qual é representado. Muitos se apropriam da autoimagem negativa que a sociedade lhes impõe e da exclusão socioeconômica que o próprio cenário produtivo capitalista gera. Quando deixa o trabalho informal e passa a atuar em cooperativa no modo autogestionário, leva consigo o que foi vivido e aprendido nas ruas, seus valores e seus costumes, o que se constitui em entraves para o processo de produção do conhecimento.

Ao se deparar com essa realidade, os gestores de incubação atuam inicialmente para a sensibilização dos catadores, respeitando sua própria identidade cultural e suas visões de mundo. Faz-se necessário primordialmente promover sua identidade, para que se apropriem da informação (atribuir significado) e da nova proposta de trabalho, evoluindo, assim, e se fortalecendo em suas conquistas e processos de superação. Ou seja, a apropriação da informação passa pela (re)(des)construção de identidade.

Esse processo de superação é possível quando o sujeito no processo de incubação passa pelo desenvolvimento gradativo de problematização e autoafirmação. Freire (2014, p. 229) explica que problematizar é “[...] exercer análise crítica sobre a realidade problema.”. Trata-se, dessa forma, de um momento de confronto com a realidade e de conscientização. Quanto mais se problematizam os sujeitos, mais se sentirão desafiados e provocados para novas compreensões.

Para Gadotti (1996), a conscientização é ação transformadora que se alcança com o diálogo crítico, a fala e a convivência. À medida que os sujeitos desenvolvem sua postura crítica e refletem sobre si e sobre o mundo, ampliam seu campo de sua percepção.

Portanto, o catador, ao ser possibilitado refletir sobre sua condição e existência, pode percebê-las como uma situação que é objetivamente problemática e vir a comprometer-se com sua transformação. Para tanto, o 
sujeito emerge do local em que se encontrava mergulhado e adquire capacidade de atuar e intervir em sua realidade histórica e cultural, na medida em que esta é percebida e desvendada. A intervenção na realidade representa o passo à frente para a conscientização.

Entende-se que a apropriação da informação pelo catador cooperado se efetua a partir do momento em que ele toma para si o conhecimento produzido e modifica as estruturas do seu pensamento, produzindo e ampliando novos significados para a cooperativa. Nesse ambiente de aprendizagem e construção de significados, ele ressignifica e promove sua identidade.

\subsection{Ressignificação da identidade: de catadores para agentes ambientais}

A construção da identidade do indivíduo está estritamente ligada ao ambiente no qual se desenvolve e às relações que o circulam, bem como à cultura que ele produz e que ao mesmo tempo também o produz. Logo, não se trata de algo pronto ou acabado, mas que significa e se ressignifica, se desloca e se forma em relação às formas como é representada nos sistemas culturais simbólicos em que se insere (HALL, 2006). Representa, por conseguinte, significado cultural e socialmente atribuído.

De forma expressiva, dada a natureza da atividade desempenhada, o catador ainda é marginalizado pela sociedade. Todos recebem classificações estereotipadas por lidarem com resíduos sólidos, comumente "denominados" de lixo. São indivíduos estigmatizados, confundidos com mendigos e considerados potencialmente perigosos. A começar pelo visual, cor da pele, forma de se vestir e pelos sinais de precariedade em relação à saúde.

Esses indivíduos vivem à margem da sociedade e são marcados pela exclusão e pela diferença. Isso se deve ao fato de, em sua identidade, aparecerem símbolos que, nas relações sociais, permitem identificá-los como catadores. Por lidarem com o "lixo", um elemento indesejado pela humanidade, são relacionados à "gente suja".

Woodward (2012) pontua que a identidade é tanto simbólica como social. É sinalizada por sistemas classificatórios que produzem padrões simbólicos e acarretam a exclusão. Uma vez que a identidade e a diferença são 
criações sociais e culturais, o resultado do processo de produção simbólica e discursiva tem, portanto, estreita conexão com as relações de poder.

Sendo assim, as metodologias criativas de incubação permitem inserir os catadores no processo de problematização, o que favorece a compreensão da estrutura social e cultural em que se encontram e possibilita a ressignificação de suas identidades. Ao compreenderem o seu papel social na comunidade em que vivem, é possível passar de catadores a agentes ambientais.

De modo objetivo, ao se apropriar do discurso ambientalista em busca de um modelo de identidade, o indivíduo supera a injustiça simbólica a que está submetido. É o que se observa no depoimento do catador (A): “[...] bom, eu acho interessante pra poder ajudar o meio ambiente. Isso é importante, né. [...] me sinto uma agente ambiental".

Acredita-se na possibilidade de que, gradativamente, de mero espectador e herdeiro das condições em que se encontra, o catador alce a categoria de agente transformador. E isso será possível por meio do empoderamento e da comunicação, cujo movimento ocorre de dentro para fora, transformando atores sociais excluídos em sujeitos ativos (SILVEIRA, 2006).

Em face do exposto, também ficou evidente que os catadores inserem o contexto da reciclagem em suas famílias, conforme assinala catador (B):

[...] lá em casa, eu separo material pra trazer pra cá, plástico, papéis, vidro. Tudo eu sempre separo. É ótimo, faz muita diferença. É uma coisa que passa pros filhos da gente. Eles mesmos já perguntam: "Mãe, posso levar isso aqui?" [risos]. Já estão aprendendo já.

Esta ação indica mudanças significativas em seu comportamento e reforça o reconhecimento, a valorização e o novo significado dado ao trabalho. Além disso, a representação da cooperativa é elemento para formação da identidade do sujeito e também inclui modos de significação, principalmente porque oportuniza a distinção entre catador associado e o catador de rua.

Infere-se, então, que o deslocamento da identidade dos sujeitos no modo de construção do conhecimento, em conjunto com os gestores de incubação, promove sua ressignificação, dando novo sentido ao trabalho e à representação da cooperativa. Esse movimento de interação em que o catador está inserido 
permite o desenvolvimento de suas relações, seu sentimento de pertença, e legitima sua identidade como agente ambiental.

\subsection{As relações de pertencimento ao lugar como afirmação da ressignificação da identidade do catador}

O conceito de pertencimento explica-se na relação do ser humano com o seu entorno. Segundo Valle (2002), trata-se dos laços que prendem o sujeito ao modo de ser, aos comportamentos e estilos do grupo a que pertence. Nessa perspectiva, refere-se ao enraizamento do indivíduo que constrói e é construído como parte de um local (KOURY, 2010).

Vale assinalar que as cooperativas trazem significados que são incorporados pelo indivíduo em sua própria identidade mediante os vínculos afetivos. É o lugar produzido pelas relações e ações dialéticas do catador com esse espaço, em que a história e a cultura criam redes de significados e sentidos vinculados à produção da vida (CARLOS, 2007).

Desse modo, na medida em que o catador se apropria da informação e produz conhecimento, a cooperativa ganha significados por intermédio do processo de identificação. É pelo processo de identificação que o catador cooperado produz o seu espaço, sua história no local, seu cotidiano, seus vínculos e desenvolve seus valores.

Ao imergirem no processo de comunicação dialética, no desenvolvimento do sentimento de pertença e no processo de apropriação da informação, os catadores legitimam sua identidade. Alguns cooperados deixam isso claro ao relatarem que cuidam da cooperativa como cuidam de seus lares, conforme afirmação do catador (C): “[...] com o mesmo amor que eu cuido da minha casa, quero cuidar disso aqui também. É assim que estamos unidos”.

O depoimento revela que o catador cooperado atribui sentidos positivos ao ambiente em que está inserido. Entretanto, para alguns, há manifestações de resistências nesse processo. Isso porque a posição escrava do catador antes de se tornar cooperado fortalece sua baixa autoestima. Além disso, o indivíduo desenvolve uma relação afetiva à realidade histórico-cultural já vivida nas ruas e estabelece afetos com lugares em que circulava e com os companheiros que 
compartilham as mesmas lutas. Assim, existem algumas rejeições no território de trabalho, como é observado no depoimento de uma jovem catadora:

[...] tem mais de 20 anos que trabalho. Assim, foi o primeiro trabalho da minha vida, catar papel na rua né, desde pequena eu fui praticamente criada dentro de um depósito de papel e tenho muito orgulho. Assim eu era mais feliz quando eu morava em um depósito de papel do que aqui nas casinhas, sinceramente. (Catadora D).

Nota-se que existe afeto estabelecido com o local em que morava e com os demais catadores com que compartilhava a vida. Salomoni (2009), ao abordar a transferência forçada do indivíduo do local de residência, refere que essa suposta transferência representa a triste perda de vínculos de vizinhança e do sentido de continuidade dos sujeitos.

A catadora estava inserida no ritmo de vida constitutivo do habitus que é formado no espaço específico de suas relações sociais (BOURDIEU, 2008). Portanto, era guiada pelo sistema de disposições socialmente constituídas e incorporadas em suas estruturas. Quando passa a trabalhar em cooperativa e em local diferente de moradia, passa a viver um conflito e desalinhamento de socialização que é incompatível com seu habitus primário. O "ser feliz no galpão" resulta do processo de socialização agradável e alinhado com o que se esperava de seu comportamento, o que impede que a catadora tenha encontros desagradáveis, isto é, encontros em que as expectativas em relação ao seu comportamento sejam agressivas em relação as suas disposições de agir.

Além do mais, o trabalho em cooperativa exige mudança nos valores e princípios que orientam o comportamento humano para uma atividade econômica de cooperação e não competição.

Conforme alguns depoimentos e com base no entendimento de que o sentimento de pertença se desenvolve a partir do processo de identificação (construção do espaço), destaca-se em síntese que o processo de legitimação do catador na cooperativa está relacionado:

a) a contextualização histórica como catador, visto que alguns cooperados já exerciam a atividade como catadores informais nas ruas. Por apresentarem uma história marcada de luta e sobrevivência 
na prática dessa atividade, tornam-se grandes defensores da valorização da categoria e da organização cooperativa;

b) ao sentimento de valorização, motivação do trabalho. Isso porque alguns evidenciam de forma efetiva que o seu trabalho na cooperativa é valorizado. A identidade passa pelo deslocamento dependente do papel que exerce em seu contexto profissional. É o "pertencer" relacionado à "voz", oportunidade de fala e confiança;

c) ao sentimento de acolhimento "familiar", visto que alguns catadores nas cooperativas se sentem em família. Vale assinalar que a cooperativa exerce valor simbólico significativo na vida pessoal do cooperado, por conta do vínculo afetivo com os demais. Outra dimensão peculiar observada no cotidiano das cooperativas em estudo é o aspecto lúdico. As brincadeiras e piadas uns com os outros ocorrem frequentemente durante o trabalho e sobre sua própria condição. Apesar das dificuldades, existe bom humor, o que fortalece a união. Os catadores têm liberdade de expressão e isso favorece o sentido positivo do trabalho.

Diante do exposto, é possível pontuar que as relações de pertencimento ao lugar favorecem a ressignificação da identidade do catador. O processo de problematização e o estabelecimento de relações e vínculos auxiliam em sua definição e possibilitam a atribuição de novos significados. O encontro dessa dimensão entre o ambiente físico e o sujeito produz o sentimento de pertença, cujos indicadores são o fortalecimento de identidade, o compromisso, a apropriação e os afetos (SALOMONI, 2009).

\section{Considerações}

Os resultados desta pesquisa evidenciam a necessidade de intensa interação para o processo de construção de conhecimento do catador inserido no contexto de incubação social. Ambas as partes precisam estar imersas no processo comunicacional dialético.

No desenvolver das interações, as estratégias dialógicas criam possibilidades de construção e ressignificação de sentido do catador. Trata-se da 
problematização como acionamento para a construção de novas possibilidades ao pensar, em movimento contínuo de perceber, refletir, agir, modificar. É o que permite aos participantes poderem se reconhecer como condutores de sua ação e da própria possibilidade de "ser mais".

As relações estabelecidas excluem os mecanismos de manipulação e geram caminhos para a construção do conhecimento em conjunto. Isso mostra que a interação se dá de forma significativa, mesmo esbarrando em algumas dificuldades para o seu desenvolvimento.

Agregados às cooperativas, os catadores amadurecem sua autoestima e ressignificam sua identidade diante das situações e imagens que desejam superar. E isso se dá a partir da vivência no e para o trabalho e da valorização do seu papel social como trabalhadores. Também foi possível observar que a identidade dos grupos se encontra em processo de formação, tendo em vista as complexas tensões e fragilidades a que estão submetidos. Nesse processo de formação, os sujeitos atribuem significados e valores ao espaço de trabalho e à construção de laços sociais.

Importante considerar que a incubação social não é um projeto realizado por módulos para chegar à “desincubação". É, em vez disso, um modo embrionário que exige tempo, dedicação, respeito à diversidade e reconhecimento de que ambos (agentes de incubação social e catadores) são detentores de saberes (científicos/populares).

Conforme percebido, configura-se caminho diferente e inverso, que se constrói por meio da experimentação e com bases constantemente adaptadas. É um processo que rompe limites iniciais de sucessivos descobrimentos mútuos entre o catador e agentes de incubação, de construção e reconstrução de conhecimentos em que um se alimenta do outro.

Além disso, a relação estabelecida para esta construção baseia-se na realidade vivenciada pelo catador, afinal, as cooperativas também são espaços de legitimação de conhecimento. As pessoas criam métodos, formas e meios de sobrevivência, produzem conhecimentos mediante crenças e práticas populares, o que propicia o desenvolvimento de seu espaço histórico-social. 
Seguindo esse raciocínio, cabe enfatizar que os dados expostos sequencialmente não representam o processo linear de transformação dos catadores. O sujeito precisa estar inserido nas aberturas dialógicas e problematizações proporcionadas pelo processo comunicacional. É dessa maneira que desenvolvem seus sentimentos de pertença, ressignificam sua identidade e se apropriam da informação em ordens distintas ou ao mesmo tempo, como mostra a Figura 1.

Figura 1 - Contexto de Incubação social

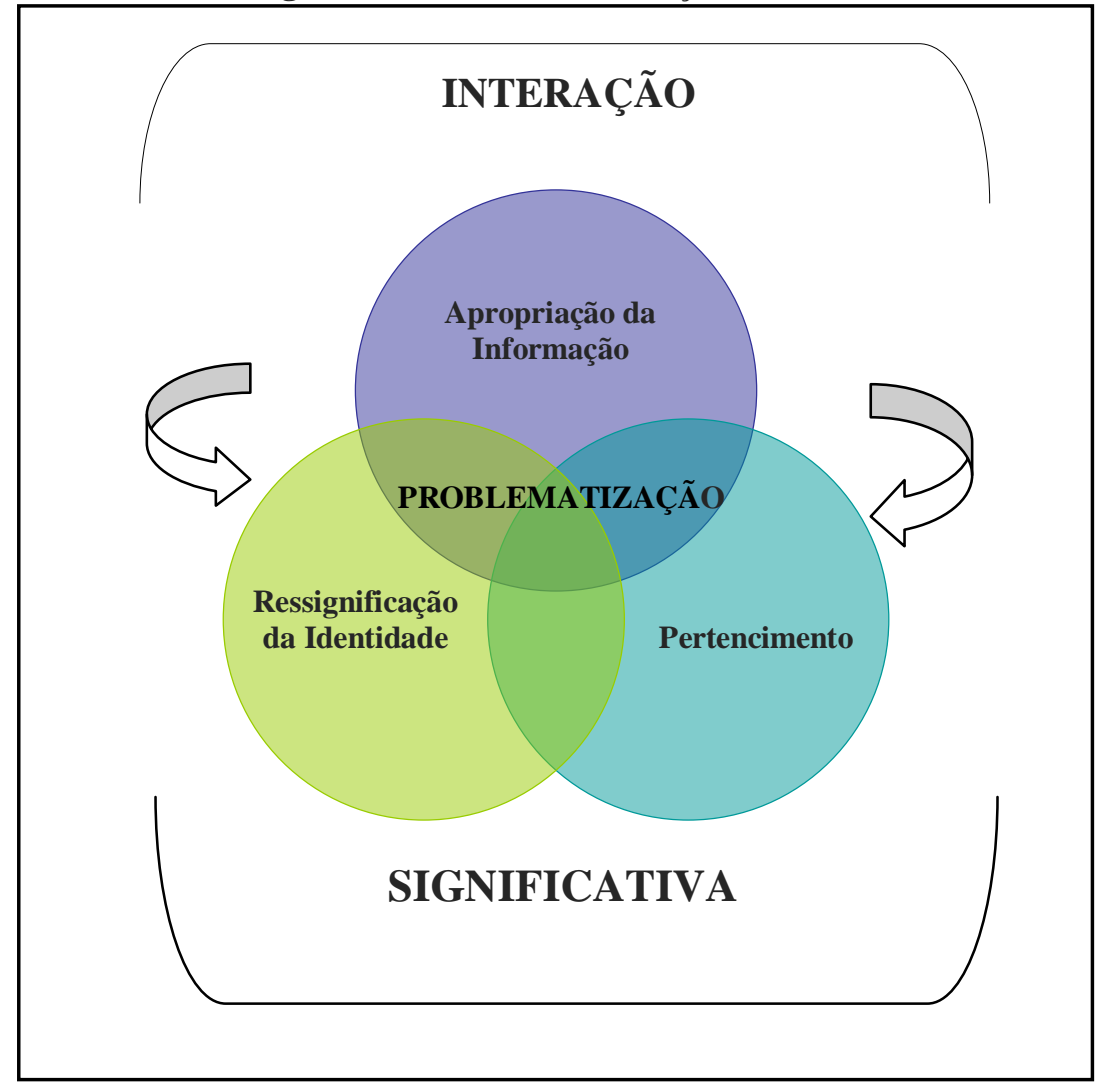

Fonte: Elaborado pelas autoras.

No contexto de incubação social, o catador é inserido em estratégias dialógicas criativas. Ao se problematizar, apropria-se das aberturas que o diálogo proporciona e se desenvolve gradativamente como agente de transformação de sua realidade. Entende-se que a apropriação, ressignificação e o pertencimento estão entrelaçados e apresentam como centro a problematização. Isto é, o catador pode despertar consciência crítica no contexto de cada elemento apresentado. 
Uma vez que os objetivos do estudo foram alcançados, acredita-se que esta pesquisa traga subsídios para a reflexão inicial da realidade dos catadores como agentes de transformação. Na condição de detentores de saberes preciosos sobre a atividade que exercem, o seu processo de construção de conhecimento é diferenciado, dada a realidade em que vivem.

A pesquisa sinalizou indicativos para investigações futuras sobre o tema, principalmente sobre a equipe gestora do programa de incubação social, no que diz respeito ao tratamento dado à extensão universitária e à participação de docentes e discentes em projetos dessa natureza.

\section{Referências}

BOURDIEU, Pierre. Razões práticas: sobre a teoria da ação. Campinas: Papirus, 1996.

BOURDIEU, Pierre. Las formas del capital. Lima: Piedra Azul, 1999.

BOURDIEU, Pierre (Coord.). A miséria do mundo. 17. ed. Petrópolis: Vozes, 2008.

CARLOS, Ana Fani Alessandri. O lugar no/do mundo. São Paulo: FFLCH, 2007.

CULTI, Maria Nezilda. Conhecimento e práxis: processo de incubação de empreendimentos econômicos solidários como processo educativo. Otra Economía: revista latinoamaericana de economía social y solidaria, São Leopoldo, v. 3, n. 5, p. 146-165, 2009. Disponível em:

<http://revistas.unisinos.br/index.php/otraeconomia/article/view/1163>. Acesso em: 20 maio 2015.

DIEHL, Astor Antônio; TATIM, Denise Carvalho. Pesquisa em ciências sociais aplicadas: métodos e técnicas. São Paulo: Prentice Hall, 2004.

ETZKOWITZ, Henry. Hélice tríplice: universidade-indústria-governo: inovação em movimento. Porto Alegre: EDIPUCRS, 2013.

FÓRUM DE PRÓ-REITORES DE EXTENSÃO DAS UNIVERSIDADES PÚBLICAS BRASILEIRAS (FORPROEX). Política Nacional de Extensão Universitária. Manaus, 2012. (Coleção Extensão Universitária, 1). Disponível em: <https://www.ufmg.br/proex/renex/images/documentos/2012-07-13Politica-Nacional-de-Extensao.pdf>. Acesso em: 16 dez. 2016. 
FRANÇA, Vera Veiga; MARTINO, Luiz C.; HOHLFELDT, Antonio. Teorias da comunicação: conceitos, escolas e tendências. 2. ed. Petrópolis: Vozes, 2002.

FREIRE, Paulo. Extensão ou comunicação? 16. ed. Rio de Janeiro: Paz e Terra, 2013.

FREIRE, Paulo. Pedagogia do oprimido. 56. ed. Rio de Janeiro: Paz e Terra, 2014.

GADOTTI, Moacir. Economia solidária como práxis pedagógica. São Paulo: EDL, 2009.

GADOTTI, Moacir. Paulo Freire: uma biobibliografia. São Paulo: Instituto Paulo Freire, 1996.

GOMES, Suely Henrique de Aquino. Inovação tecnológica no sistema formal de comunicação científica: os periódicos eletrônicos nas atividades de pesquisa de acadêmicos de pós-graduação no Brasil. 1999. Tese (Doutorado) - Faculdade de Ciência da Informação, Universidade Federal de Brasília, 1999. Disponível em:

<http://enancib.ibict.br/index.php/enancib/ivenancib/paper/viewFile/2701/1829 >. Acesso em: 21 jan. 2017.

HALL, Stuart. A identidade cultural na pós-modernidade. 11. ed. Rio de Janeiro: DP\&A, 2006.

KOURY, Mauro Guilherme Pinheiro. Identidade e pertença: disposições morais e disciplinares em um grupo de jovens. Etnográfica, Lisboa, v. 14, n. 1, p. 2758, jan. 2010.

LIMA, Venício Artur de. Comunicação e cultura: as idéias de Paulo Freire. 2. ed. Rio de Janeiro: Paz e Terra, 1981.

MORIN, Edgard. O método: 4: as idéias: a sua natureza, vida, habitat e organização. Porto Alegre: Europa-América, 1991.

PETERS, Gabriel. O social entre o céu e o inferno: a antropologia filosófica de Pierre Bourdieu. Tempo Social, São Paulo, v. 24, n. 1, p. 229-262, jan. 2012. Disponível em: <http://www.revistas.usp.br/ts/article/view/48867/52942>. Acesso em: 15 abr. 2017.

SALOMONI, Salete Maria. Moradores do universo: afetos e significados da relação exclusão/inclusão social em programas de melhoramento urbano. 113f. 2009. Dissertação (Mestrado em Psicologia) - Centro de Ciências Humanas, Universidade de Fortaleza, Fortaleza, 2009. 
SAMPAIO, Juliana et al. Limites e potencialidades das rodas de conversa no cuidado em saúde: uma experiência com jovens no sertão pernambucano. Botucatu: Interface, 2014.

SANTOS, Boaventura de Sousa (Org.). Produzir para viver: os caminhos da produção não capitalista. 2. ed. Rio de Janeiro: Civilização Brasileira, 2005.

SILVEIRA, Fialho. Emponderamento e a constituição de capital social entre a juventude. In: BAQUERO, Marcelo; CREMONESE, Dejalma. Capital social: teoria e prática. Ijuí: Unijuí, 2006. p. 251-275.

VALLE, Edênio. Conversão: da noção teórica ao instrumento de pesquisa.

Revista Eletrônica de Estudos da Religião, São Paulo, n. 2, p. 51-73, 2002.

Disponível em: <http://www.puc.br/rever/rv2_2002/t_valle.htm>. Acesso em: 6 jan. 2016.

WOODWARD, Kathryn. Identidade e diferença: uma introdução teórica e conceitual. In: SILVA, Tomaz Tadeu da. Identidade e diferença: a perspectiva dos estudos culturais. Petrópolis: Vozes, 2012. p. 7-72.

\title{
Appropriation of information: the process through construction of knowledge collectors of recyclable material
}

\begin{abstract}
The aim of this research is to understand the construction process of knowledge developed by people who catch recyclable waste material, also known as either waste pickers or collectors, organized in Cooperatives and advised by a Social Incubation Project at the Federal University of Goiás, from the tension between scientific and common knowledge. Concerning to the methodological aspects, the research has a qualitative approach and regarding the goals, it is characterized as descriptive - exploratory. The data were collected through participant observation. Through the obtained data, it is considered that the construction of knowledge of those waste pickers inserted in the social incubation context happens through some meaningful interaction. That is, via dialogue and immersed in creative methodological strategies, the subject changes the message into some relevant information, causing modifications in his symbolic basis of knowledge. This transformation is only through a communicative process. It is in his interaction that the subject is questioned by performing a critical analysis on his current reality as a collector, which enables him to create a new meaning to his own identity, develops his sense of belonging and linkages with the group he works with, and gets appropriation of the information that is mediated by the Incubation Team Manager.
\end{abstract}

Keywords: Communication. Production of knowledge. Appropriation of information. Social Incubator. Collectors of recyclable material. 
Apropriação da informação: o processo de construção do conhecimento de catadores de materiais recicláveis Suely Henrique Gomes, Geisa Müller de Campos Ribeiro, Laura Vilela Rodrigues Rezende

Recebido: 31/01/2017

Aceito: 13/05/2017 